\title{
ANÁLISE DA VIABILIDADE ECONÔMICA DO POLICULTIVO DE CARPAS, JUNDIÁS E TILÁPIAS-DO-NILO COMO UMA ALTERNATIVA DE MODELO DE CULTIVO DE PEIXES PARA PEQUENAS PROPRIEDADES
}

\author{
RITTER, F.1,2,3; PANDOLFO, A. ${ }^{1}$; BARCELLOS, L.J.G.'; QUEVEDO, R.M. ${ }^{2}$; SANTOS-RITTER, V.R.S. ${ }^{3}$; \\ GOMES, A.P. ${ }^{*}$, MARCONDES-PANDOLFO, L. ${ }^{1}$ \\ 1 - Faculdade de Engenharia e Arquitetura, Universidade de Passo Fundo (UPF), Campus I, Caixa \\ Postal 611, Bairro São José. 99001-970. Passo Fundo, RS, Brasil. \\ 2 - Faculdade de Agronomia e Medicina Veterinária, Universidade de Passo Fundo (UPF), Campus I, \\ Caixa Postal 611, São José. CEP 99001-970. Passo Fundo, RS, Brasil. \\ 3 - Curso de Medicina Veterinária, Instituto de Desenvolvimento Educacional do Alto Uruguai \\ (IDEAU), Campus II, Rua Jacob Gremmelmaier 215, Centro. 99900-000. Getúlio Vargas, RS, Brasil. \\ *Corresponding author: alinegomes1977@hotmail.com
}

\begin{abstract}
Ritter, F.; Pandolfo, A.; Barcellos, L.J.G.; Quevedo, R.M.; Santos-Ritter, V.R.S.; Gomes, A.P. (2013) Analysis of economical viability of fish policulture with carp, silver catfish and Nile tilapia as an alternative of the fish farming model in small farms. Braz. J. Aquat. Sci. Technol. 17(2):27-35. elSSN 1983-9057. DOI: 10.14210/bjast.v17. n2.p27-35. With a growing world population and increasing demand for quality food in sufficient quantities, aquaculture fits in this context as an active producer of high quality animal protein in large quantities by field use. The production of fish in farm ponds has been practiced for over five decades in Rio Grande do Sul, and the system is commonly used in carp polyculture, which consists of intercropping different species of carp to improve the performance of each one and therefore achieve greater productivity. But the carp polyculture currently used has a low technological level, the production obtained is considered small. Studies have been performed by adding the silver catfish to the traditional polyculture, thus obtaining good results. Some studies were performed on economic viability, but with a single species, or consortium, as is the case of polyculture of shrimp and Nile tilapia. This study tested the polyculture with partial substitution $25 \%, 50 \%$ and $75 \%$ of silver catfish and carp by Nile tilapia. The economic viability of all polycultures studied were analyzed under the condition of certainty by obtaining the Net Present Value (NPV), Annual Value (AV), Internal Rate of Return (IRR) and Payback. It was concluded that replacing $25 \%$ of silver catfish and carp by Nile tilapia has higher biomass production and that an investment in polyculture with vita useful 25 years is economically feasible for a fee Minimum Attractiveness (TMA) of 6.17\%.
\end{abstract}

Keywords: Fish polyculture, fish farming viability, small farms fish farming, carp, catfishe, Nile tilapia.

\section{INTRODUÇÃO}

A população mundial vem crescendo de maneira acelerada, gerando assim a necessidade de produção de alimentos de qualidade e em quantidade capaz de suprir a crescente demanda, necessitando desta forma investimento em pesquisa, como por exemplo, de cultivos alternativos para a produção de alimentos.

A aquicultura se encaixa neste contexto como atividade produtora de proteína animal de alta qualidade e em grande quantidade por área utilizada. A aquicultura no Brasil vem se destacando nos últimos anos, principalmente na área de piscicultura, sendo que a produção de peixes representa $48 \%$ de uma produção aquícola de 62959046 toneladas (FAO, 2007).

O policultivo de carpas é um dos sistemas de cultivo mais utilizados no mundo. Neste cultivo todas as espécies de carpas têm importante papel para o aproveitamento do alimento natural produzido no viveiro. As carpas-capim (Ctenopharyngodon idella) consomem as plantas macrófitas e as suas fezes contribuem para a adubação do tanque. A carpa húngara (Cyprinus carpio) revolve o fundo, liberando nutrien- tes para a água, que por sua vez contribuem para o desenvolvimento de plâncton, que também serve de alimento para a carpa cabeça-grande (Aristichthys nobilis) e para a carpa prateada (Hipophtalmicrthys molitrix), que tem papel vital no controle das algas. Por isso, todas as espécies são importantes para o maior aproveitamento do viveiro.

Souza \& Barcellos (1998) afirmaram que o policultivo pode elevar a produção do reservatório por utilizar totalmente a cadeia alimentar, diminuindo o custo em ração. Neste sistema, as espécies de peixes utilizadas ocupam todas as camadas do tanque: superior, média e inferior, e o hábito alimentar de cada espécie é diferente, evitando que haja competição por alimento.

Silva (2008) analisou a possibilidade de implantação de um novo sistema de cultivo, substituindo parcialmente as carpas por jundiás e tilápias-do-Nilo, obtendo com isso, bons resultados quanto à produtividade, que foi aumentada significativamente.

O jundiá (Rhamdia quelen) é um peixe onívoro com leve tendência carnívora (Gomes et al., 2000), mas também se alimenta de plâncton maior e bentos. 
No policutivo, tem o papel de predador para controle na reprodução natural da carpa húngara.

Segundo Barcellos et al. (2003), o jundiá é uma espécie apropriada para a produção em regiões onde o clima temperado e subtropical é o predominante.

A utilização da tilápia-do-Nilo juntamente com as carpas prateadas e cabeça-grande, ou no lugar destas, baseia-se no fato de que também são filtradoras e apresentam rápido ganho em peso na época mais quente e tem boa aceitação no mercado.

A consorciação de tilápias-do-Nilo com carpas é comum em sistemas semi-intensivos de produção com base em fertilização, pois a combinação de tilápia-do-Nilo, carpa comum e carpa prateada maximizam a utilização do alimento natural disponível (Abdelghany \& Ahmad, 2002).

As regiões norte e noroeste do estado do Rio Grande do Sul apresentam importantes bacias hidrográficas. O modelo de cultivo mais difundido atualmente nessas regiões é o policultivo de carpas, sendo a espécie principal a carpa húngara e as complementares, as carpas chinesas, capim, cabeça-grande e prateada em percentuais variados de acordo com o mercado e disponibilidade de alimento.

Segundo o Instituto Brasileiro do Meio Ambiente e dos Recursos Renováveis (IBAMA), em 2005 o Rio Grande do Sul produziu 23314 toneladas de peixes de água doce, $90 \%$ dos peixes foram carpas de sistemas de policultivo , $8 \%$ foram de tilápias-do-Nilo, e 1,54\% foram jundiá .

Além do baixo nível tecnológico da piscicultura desenvolvida no norte e noroeste do estado, que resulta na baixa produção de biomassa, não há dados precisos sobre a viabilidade econômica do policultivo tradicional de carpas e nenhum estudo sobre a viabilidade econômica do policultivo de carpas, jundiás e tilápia-do-Nilo

Costa (2008) realizou a avaliação econômica do sistema de policultivo de camarões marinhos (Litopenaeus vannamei) com tilápia (Oreochromis niloticus) em diferentes densidades de estocagem. Alguns pesquisadores analisaram a viabilidade econômica para determinadas espécies em separado, como é o caso do estudo realizado por Graeff et al. (2001) que verificou a viabilidade econômica para o cultivo de carpa comum (Cyrpinus carpio).

A análise da viabilidade econômica de um projeto permite fazer estimativas de todo o gasto envolvido com o investimento inicial, operação e manutenção e receitas geradas durante um determinado período de tempo, para assim montar-se o fluxo de caixa relativo a esses investimentos, custos e receitas e determinar as estimativas dos indicadores econômicos do projeto (Lindemeyer, 2008).
Há diferentes formas de medir a rentabilidade de um projeto, Buarque (2004) cita: a Taxa Interna de Retorno (TIR), o Valor Presente Líquido (VPL) e o tempo de retorno do capital (payback). Além destas formas, utiliza-se também o Valor Anual (VA).

Segundo Cohen \& Franco (2000), a TIR representa a rentabilidade média do dinheiro utilizado no projeto durante toda a sua duração. É a taxa que torna nulo o VPL do fluxo de caixa do investimento, logo, é a taxa que torna o valor presente dos lucros futuros equivalentes aos dos gastos realizados com o projeto, caracterizando, assim, a taxa de remuneração do capital investido. É considerado rentável o investimento que apresentar TIR > TMA (Taxa Mínima de Atratividade), que é a taxa mínima a ser alcançada em determinado projeto; caso contrário, o mesmo pode ser rejeitado.

O VPL é um dos instrumentos mais utilizados para se avaliar propostas de investimentos de capital. Reflete a atratividade, em valores monetários, do investimento medida pela diferença entre o valor presente das entradas de caixa e o valor presente das saídas de caixa, a uma determinada taxa de desconto. É considerado atraente todo o investimento maior ou igual a zero (Kassai et al., 2000). A escolha entre as diversas variantes rentáveis e comparáveis de um mesmo projeto (alternativas mutuamente exclusivas) recairá, de acordo com esse critério, sobre aquela que tiver o maior VPL (Galesne et al., 1999).

Segundo Pereira (2009), o payback do investimento indica quando será recuperado o investimento realizado, ou seja, em quanto tempo o dinheiro investido retornará. É realizado analisando o fluxo de caixa e quando os investimentos (fluxos negativos) se anularem com as entradas de caixa (receitas), então se terá o período de payback. Como o payback simples não considera o custo de capital, a soma dos saldos do investimento pode ser feita com base nos valores nominais (Bruni \& Famá, 2003). De acordo com Lindemeyer (2008), para minimizar os riscos de se utilizar um método que não leva em consideração o fator tempo, o payback é utilizado juntamente com os métodos do VPL e TIR no processo de tomada de decisão.

O método do VA consiste em achar a série uniforme anual equivalente ao fluxo de caixa dos investimentos à TMA, ou seja, encontra-se a série uniforme a todos os custos e receitas para cada projeto utilizando-se a TMA. O melhor projeto é aquele que tiver o maior saldo positivo (Casaratto Filho \& Kopittke, 1988).

A análise de investimentos em situação de certeza corresponde à previsibilidade de um resultado final certo ou esperado como tal. Ao se analisar 
um investimento sob essa ótica, se escolherá o que proporcionar maior retorno.

O objetivo deste artigo é avaliar economicamente a implantação de um policultivo tradicional de carpas e a implantação de três policultivos alternativos de carpas, jundiás, tilápias-do-Nilo visando oferecer aos produtores de peixes uma alternativa de policultivo, com espécies de valor comercial e maior produtividade.

\section{MATERIAL E MÉTODOS}

Este estudo foi realizado durante os meses de novembro de 2009 a maio de 2010 em Passo Fundo, RS. O município possui altitude de 687 metros acima do nível do mar e clima temperado com característica subtropical úmido, com chuvas bem distribuídas durante $o$ ano. Possuí uma temperatura média anual de $17,5^{\circ} \mathrm{C}$, com uma umidade relativa do ar de $72 \%$, média anual (Passo Fundo, 2009).

\section{Determinação da melhor proporção de alevinos de carpas, jundiás e tilápias-do-Nilo}

Em todos os experimentos foram utilizados jundiás e carpas criados e mantidos no Laboratório de Piscicultura da Universidade de Passo Fundo e tilápias-do-Nilo adquiridas em fornecedores da região. Foram usados 15 tanques escavados de $180 \mathrm{~m}^{2}$ e $1,2 \mathrm{~m}$ de profundidade média e 4 tanques de 3500 a $5000 \mathrm{~m}^{2}$.

Utilizaram-se diferentes porcentagens de substituição das carpas pelo jundiá e pela tilápia-do-Nilo (Tabela1).

Os alevinos das carpas e jundiás possuíam comprimento médio de $4,5 \pm 0,5 \mathrm{~cm}$, pesando em média $1,0 \pm 0,5 \mathrm{~g}$. Os alevinos das tilápias-do-Nilo mediam cerca de $7 \pm 1 \mathrm{~cm}$ de comprimento e pesavam cerca de $6 \pm 1 \mathrm{~g}$.

A alimentação dos peixes obedeceu ao seguinte roteiro:

Alimentos:

a. capins tenros para carpas capim, inicialmente triturados e a partir dos 120 dias, inteiros; b. grãos de milho para as carpas húngaras, inicialmente triturados e a partir dos 120 dias, inteiros, sempre colocados para inchar em água 60 minutos antes da alimentação;

c. ração para jundiás e tilápias, dieta seca comercial para alevinos com $42 \%$ PB em pellets de 1 - $2 \mathrm{~mm}$ até os 60 dias, passando para extrusada de $3-4 \mathrm{~mm}$ até 120 dias e depois para extrusada de $4 \mathrm{~mm}$ e $32 \%$ PB até a terminação;

d. fito e zooplâncton obtidos através de sistema de adubação.

Para se efetuar a alimentação dos peixes, utilizou-se uma taxa de alimentação baseada no peso médio obtido em biometrias, conforme apresentado na Tabela 2.

Frequência:

Os animais receberam alimentação com frequência de duas vezes ao dia, no horário das $11 \mathrm{~h} 00 \mathrm{~min}$ e $16 \mathrm{~h} 00 \mathrm{~min}$.

Manejo alimentar:

Primeiro foi colocado o capim (variável de acordo com a época, mas sempre priorizando capins novos, em fase de crescimento) e os grãos para as carpas húngaras e 60 minutos depois a ração complementar para as tilápias e/ou jundiás.

Para o preparo dos tanques para o cultivo foi realizada a análise de solo do fundo dos viveiros para determinar a quantidade exata de adubo orgânico e mineral para cada tanque experimental. A calagem foi feita sobre fundo seco numa proporção de 4 a 6 toneladas por hectare de acordo com o pH do solo. A adubação inicial foi feita com o viveiro seco, usando 2 a 3 toneladas por hectare de cama de aviário. Durante o período de cultivo, como adubação de manutenção, utilizou-se mais 2 a 3 toneladas de cama de aviário de acordo com transparência por disco de Secchi e demais parâmetros de qualidade de água.

Com os tanques já cheios, a adubação orgânica foi complementada com adubos minerais, sulfato de amônia e superfosfato triplo, conforme transparência por disco de Secchi.

Também foi realizada uma biometria quinzenal, na qual se retirava $10 \%$ dos peixes presentes

Tabela1 - Tratamentos realizados no projeto e a proporção das espécies constituintes dos policultivos.

\begin{tabular}{ccccc}
\hline \hline & $\begin{array}{c}\text { Policultivo } \\
\text { Tradicional }\end{array}$ & $\begin{array}{c}\text { P25 (25\% de } \\
\text { substituição) }\end{array}$ & $\begin{array}{c}\text { P50 (50\% de } \\
\text { substituição) }\end{array}$ & $\begin{array}{c}\text { P75 (75\% de } \\
\text { substituição) }\end{array}$ \\
\cline { 2 - 5 } Espécie & \multicolumn{2}{c}{ Proporção entre as diferentes espécies (\%) } \\
\hline Carpa húngara & 40,00 & 30,00 & 20,00 & 10,00 \\
Carpa capim & 30,00 & 30,00 & 30,00 & 30,00 \\
Carpa prateada & 15,00 & 11,25 & 7,50 & 3,75 \\
Carpa c. grande & 15,00 & 11,25 & 7,50 & 3,75 \\
Jundiá & Não utilizado & 10,00 & 20,00 & 30,00 \\
Tilápia & Não utilizado & 7,50 & 15,00 & 22,50 \\
\hline \hline
\end{tabular}

Policultivo Tradicional - controle, policultivo convencional I

P25 - policultivo com $25 \%$ de substituição da carpa húngara por jundiás e das carpas filtradoras por tilápias-do-Nilo P50 - policultivo com $50 \%$ de substituição da carpa húngara por jundiás e das carpas filtradoras por tilápias-do-Nilo P75 - policultivo com $75 \%$ de substituição da carpa húngara por jundiás e das carpas filtradoras por tilápias-do-Nilo 
Tabela 2 - Taxa de alimentação dos peixes conforme faixas de peso médio. ${ }^{1,2}$

\begin{tabular}{cc}
\hline \hline $\begin{array}{c}\text { Faixa de } \\
\text { peso }(\mathbf{g})\end{array}$ & $\begin{array}{c}\text { Taxa alimentar } \\
(\% \text { da biomassa / dia) }\end{array}$ \\
\hline Até $\mathbf{2 0} \mathbf{g}$ & Até saciedade \\
$\mathbf{2 1 - 5 0}$ & $8 \%$ \\
$\mathbf{5 1 - 1 0 0}$ & $7 \%$ \\
$\mathbf{1 0 1 - 2 0 0}$ & $6 \%$ \\
$\mathbf{2 0 1}-\mathbf{3 0 0}$ & $5 \%$ \\
$\mathbf{3 0 1}-\mathbf{4 0 0}$ & $4,50 \%$ \\
$\mathbf{4 0 1 - 5 0 0}$ & $4 \%$ \\
$\mathbf{5 0 1}-\mathbf{6 0 0}$ & $3,50 \%$ \\
$\mathbf{6 0 1}-\mathbf{7 0 0}$ & $3 \%$ \\
$\mathbf{7 0 1 - 8 0 0}$ & $2,50 \%$ \\
Acima de 801 & $2 \%$ \\
\hline \hline
\end{tabular}

Fonte: Peter Garádi (TEHAG) apud Barcellos, 2006.

1. A taxa alimentar foi reduzida de acordo com a temperatura da água.

2. Esta tabela não se aplica ao pasto para carpas-capim que foi fornecido conforme observações de oferta e consumo.

no tanque de cultivo e avaliava-se a sobrevivência, o peso médio por espécie, comprimentos padrão e total médio por espécie e a uniformidade de lote.

\section{Análise da viabilidade econômica dos} policultivos de carpas, jundiás e tilápias-do-Nilo

Relacionaram-se todos os gastos do investimento inicial, composto por projetos, licenças ambientais, construção de tanques escavados, instalações físicas para depósito de equipamentos, aquisição de utensílios, máquinas e equipamentos que serão utilizados para a implantação e manutenção do policultivo. Para isto, realizou-se uma pesquisa de mercado.

Foram levantados os custos de produção, constituídos por salários, rações, adubação dos tanques, energia elétrica, aquisição de alevinos e testes de qualidade de água, e os custos para a manutenção dos tanques, que consiste na raspagem do fundo do tanque para a retirada do lodo e excesso de matéria orgânica que vai se depositando no fundo com o passar do tempo.

Para o cálculo da depreciação tomou-se por base a Nota Técnica de $n^{\circ}$ 78/2005 da Receita Federal, onde consta o prazo de vida útil para cada bem. Após determinar o custo unitário de um bem, faz-se a divisão do seu custo pela vida útil. Também foram consideradas as despesas com impostos.

Para determinação das receitas, durante o mês de maio de 2010 foi realizada uma pesquisa de mercado visando obter dados sobre o preço pago ao produtor por kg do peixe vivo, em diferentes regiões do Rio Grande do Sul.

Com base na pesquisa de preço médio pago por kg de peixe vivo no Rio Grande do Sul e os dados de produção obtidos nos ensaios experimentais de policultivos, realizou-se o cálculo da receita bruta para todos os policultivos pesquisados.

A análise da viabilidade econômica de cada policultivo foi realizada na condição de certeza, sendo calculados: o VPL, a TIR, o VA e o payback.

Para o cálculo do VPL utiliza-se a seguinte equação:

$$
V P L=I+\sum_{t=1}^{n} \frac{F C_{t}}{(1+i)^{t}}
$$

Onde I é o investimento de capital na data zero; $\mathrm{FC}_{t}$ representa o valor final na data t do fluxo de caixa; n é o prazo de análise do projeto; e, $i$ é a TMA para realizar o investimento, ou custo de capital do projeto de investimento.

Para a determinação da TIR faz-se uso da equação

$$
0=-I+\sum_{t=1}^{n} \frac{F C_{t}}{(1+T I R)^{t}}
$$

O cálculo do VA consiste em achar uma série uniforme anual equivalente (pela TMA) ao fluxo de caixa do investimento. Este VA determina o quanto este investimento retornaria anualmente a mais que a TMA.

O payback pode ser calculado conforme a Equação (3), onde se divide o Valor do Investimento Inicial pela média do fluxo de caixa anual:

$$
P B=\frac{\text { Invest.Inicial }}{\sum F C_{A n o}}
$$

Considerou-se a TMA de 6,17\%, valor baseado na rentabilidade anual da Caderneta de Poupança, visto que o pequeno produtor geralmente aplica suas economias neste tipo de investimento.

\section{RESULTADOS E DISCUSSÃO}

\section{Determinação da melhor proporção de alevinos de carpas, jundiás e tilápias-do-Nilo}

Em todos os tratamentos com diferentes substituições das carpas pela tilápia-do-Nilo e pelo jundiá houve uma produção significativamente maior em comparação com o sistema tradicional (Tabela 3).

O cultivo com $25 \%$ de substituição das carpas pela tilápia-do-Nilo e pelo jundiá mostrou-se mais produtivo em comparação aos demais, isto se deve ao melhor desempenho da carpa húngara, que apesar de ter sido substituída parcialmente, apresentou um maior ganho de peso.

Segundo Abdelghany \& Ahmad (2002), a interação entre a carpa húngara, tilápia-do-Nilo e a carpa prateada otimiza a utilização do alimento natural disponível, corroborando com isto, Kestmont (1995) 
Tabela 3 - Produção em massa (kg/ha/ano) por espécie nos, diferentes policultivos após o primeiro ciclo de produção, considerando 147 dias de cultivo e densidade final de 5000 peixes por hectare.

\begin{tabular}{lcccc}
\hline \hline \multicolumn{5}{c}{ Produção (kg/ha/ano) } \\
\hline \multicolumn{1}{c}{ Espécies } & Tradicional & $\mathbf{P 2 5}^{*}$ & $\mathbf{P 5 0}^{\text {**}}$ & $\mathbf{P 7 5}^{\text {***}}$ \\
\hline Carpa Húngara & $1.661,60$ & $2.058,40$ & $1.543,80$ & $1.413,60$ \\
Carpa-capim & 762,60 & $1.078,80$ & $1.184,20$ & 961,00 \\
Carpa Prateada & 465,00 & 468,10 & 279,00 & 179,80 \\
Carpa Cabeça-grande & 372,00 & 607,60 & 502,20 & 124,00 \\
Jundiá & Não utilizado & 248,00 & 458,80 & 564,20 \\
Tilápia & Não utilizado & 409,20 & 765,70 & $1.227,60$ \\
Total & $\mathbf{3 . 2 6 1 , 2 0}$ & $\mathbf{4 . 8 7 0 , 1 0}$ & $\mathbf{4 . 7 3 3 , 7 0}$ & $\mathbf{4 . 4 7 0 , 2 0}$ \\
\hline \hline
\end{tabular}

afirma que a produtividade de cada espécie é aumentada em um sistema de policultivo em decorrência da interação que ocorre entre elas.

Nos cultivos com $50 \%$ e $75 \%$ de substituição observou-se uma ligeira queda na produção final de pescado, que, segundo Silva et al. (2006), pode ser devido a maior substituição da carpa húngara pela tilápia-do-Nilo e pelo jundiá. Esta queda na produção está relacionada aos hábitos alimentares da carpa húngara, que revolve o fundo do tanque ao alimentarse e com isto, aumenta a transferência de oxigênio para o solo, permitindo maior reciclagem de nutrientes, os quais aumentam a disponibilidade de plâncton para as espécies filtradoras (Ritvo et al., 2004).

\section{Análise da viabilidade econômica dos policultivos de carpas, jundiás e tilápias-do-Nilo}

O investimento inicial para a implantação de um policultivo de peixes para a pequena propriedade está estimado em $R \$ 30430,00$, composto por $R \$ 24250,00$ relativos à etapa de construção civil e $R \$ 6180,00$ para equipamentos e instalação conforme apresentado na Tabela 4.

Os custos comuns de produção totalizam $\mathrm{R} \$ 872,50$ e estão apresentados na Tabela 5 , e se repetem anualmente.

A manutenção dos tanques é realizada por meio de retro-escavadeira ou trator esteira e o seu custo é de $R \$ 500,00 /$ ha a cada cinco anos.
Na Tabela 6 estão representados os itens depreciados no projeto, cada um com seu tempo de vida útil e o valor depreciado anualmente. O total das despesas anuais com depreciação foi calculado em $R \$ 1488,00$.

Atualmente o pescado está contemplado na legislação específica para produtos componentes da cesta básica por meio do Decreto $n^{\circ} 26.145$, de 21/11/2003. De acordo com os art. $1^{\circ}$, I; art. $4^{\circ}$ e $5^{\circ}$, I, o valor do ICMS sobre a comercialização do pescado pelo produtor rural é de 2,3\% sobre o valor final da venda. Neste segmento não é cobrado PIS, COFINS e Imposto de Renda, pois se trata de uma comercialização dentro do próprio estado.

A estimativa do preço de venda foi calculada considerando como a média da Região de Passo Fundo, Porto Alegre e Rio Grande (Tabela 7).

Não foram obtidos dados sobre o preço da carpa cabeça-grande, da carpa-prateada e da tilápia-do-Nilo na cidade de Rio Grande devido ao baixo número de piscicultores nesta região.

O policultivo tradicional tem um custo específico de produção anual referente a gastos com alevinos de carpas e do milho que é utilizado na alimentação destas, perfazendo um custo adicional de $\mathrm{R} \$ 4621,65$ / ano, conforme apresentado na Tabela 8.

A Tabela 9 apresenta o levantamento da receita bruta para o policultivo tradicional. Observa-se que no policultivo tradicional tem-se maior produção de carpa húngara, sendo que este pescado apresenta o menor preço de venda.

Tabela 4 - Investimento Inicial para os sistemas de policultivos estudados.

\begin{tabular}{|c|c|c|c|c|}
\hline Descriminação & Quantidade & Unidade & $\begin{array}{c}\text { Custo } \\
\text { Unitário } \\
\text { (R\$) }\end{array}$ & $\begin{array}{c}\text { Custo } \\
\text { total (R\$) }\end{array}$ \\
\hline \multicolumn{5}{|c|}{ CONSTRUÇÃO CIVIL } \\
\hline Tanques Escavados (1ha) & 1 & un & $1.750,00$ & $1.750,00$ \\
\hline Instalação para Depósito & 50 & $m^{2}$ & 340,00 & $17.000,00$ \\
\hline \multirow[t]{2}{*}{ Projeto, Taxas e licenças ambientais } & 1 & un & $5.500,00$ & $5.500,00$ \\
\hline & & & Subtotal & $24.250,00$ \\
\hline \multicolumn{5}{|c|}{ UTENSILIOS, MÁQUINAS E EQUIPAMENTOS } \\
\hline Rede Anti Pássaros & 1 & un & $3.000,00$ & $3.000,00$ \\
\hline Redes para Despesca $(12 \mathrm{~m} \times 1,5 \mathrm{~m})$ & 1 & un & $1.200,00$ & $1.200,00$ \\
\hline Balança para pesagem peixes e rações & 1 & un & 480,00 & 480,00 \\
\hline \multirow[t]{3}{*}{ Forrageira $1 / 4 \mathrm{HP}$} & 1 & un & $1.500,00$ & $1.500,00$ \\
\hline & & & Subtotal & $6.180,00$ \\
\hline & & & Total & $30.430,00$ \\
\hline
\end{tabular}


O policultivo $\mathrm{P} 25$ tem um custo específico de produção anual referente a gastos com alevinos de carpas, jundiás e tilápias-do-Nilo, com milho e ração que é utilizado na alimentação destas, perfazendo um custo adicional de $\mathrm{R} \$ 4560,27 /$ ano, conforme apresentado na Tabela 10.
$\mathrm{Na}$ Tabela 11 apresenta-se a receita bruta para este policultivo. Nesse sistema, além de carpas, também são cultivadas tilápias-do-Nilo e jundiás, que representam $8 \%$ e $5 \%$, respectivamente, do peso total da produção. Esse policultivo apresentou receita bruta cerca de $50 \%$ superior ao policultivo tradicional. Isto

Tabela 5 - Custos comuns de produção dos policultivos estudados.

\begin{tabular}{lcccc}
\hline \hline \multicolumn{1}{c}{ Discriminação } & Quantidade & Unidade & $\begin{array}{c}\text { Custo } \\
\text { unitário } \\
(\mathbf{R} \$)\end{array}$ & $\begin{array}{c}\text { Custo } \\
\text { total } \\
\text { (R\$) }\end{array}$ \\
\hline Kits para Análise de água & 2 & un & 300,00 & 600,00 \\
Adubação dos tanques & 800 & $\mathrm{~kg}$ & 0,12 & 96,00 \\
Salário Tratador/ ano & 2 & hora/dia & 68,75 & 137,50 \\
Energia Elétrica & 150 & Kwh/ ano & 0,26 & 39,00 \\
& & & Total & $\mathbf{8 7 2 , 5 0}$ \\
\hline \hline
\end{tabular}

Tabela 6 - Despesas com depreciação.

\begin{tabular}{lccc}
\hline \hline \multicolumn{1}{c}{ Item } & $\begin{array}{c}\text { Custo } \\
\text { Unitário } \\
\text { (R\$) }\end{array}$ & $\begin{array}{c}\text { Tempo } \\
\text { vida útil } \\
\text { (anos) }\end{array}$ & $\begin{array}{c}\text { Depreciação } \\
\text { anual (R\$) }\end{array}$ \\
\hline Tanques Escavados & $1.750,00$ & 25 & 70,00 \\
Instalação para Depósito & $17.000,00$ & 25 & 680,00 \\
Rede Anti Pássaros & $3.000,00$ & 10 & 300,00 \\
Redes para Despesca & $1.200,00$ & 5 & 240,00 \\
$\begin{array}{l}\text { Balança para pesagem peixes e } \\
\text { rações }\end{array}$ & 480,00 & 10 & 48,00 \\
Forrageira 1/4 HP & $1.500,00$ & 10 & 150,00 \\
& & Total & $\mathbf{1 . 4 8 8 , 0 0}$ \\
\hline \hline
\end{tabular}

Tabela 7 - Levantamento do preço pago ao produtor em três regiões do Rio Grande do Sul (Preço em R\$/kg, peixe vivo). Dados referentes ao mês de maio de 2010.

\begin{tabular}{|c|c|c|c|c|c|c|}
\hline \multirow[b]{2}{*}{ Região } & \multicolumn{5}{|c|}{ Espécie } & \multirow[b]{2}{*}{ Tilápia } \\
\hline & $\begin{array}{l}\text { Carpa } \\
\text { Húngara }\end{array}$ & $\begin{array}{l}\text { Carpa- } \\
\text { capim }\end{array}$ & $\begin{array}{l}\text { Carpa } \\
\text { Cabeça- } \\
\text { grande }\end{array}$ & $\begin{array}{c}\text { Carpa } \\
\text { Prateada }\end{array}$ & Jundiá & \\
\hline Passo Fundo & 3,00 & 4,80 & 4,80 & 4,80 & 5,50 & 4,00 \\
\hline Porto Alegre & 3,20 & 4,50 & 4,40 & 4,40 & 5,50 & 4,00 \\
\hline Rio Grande & 3,12 & 4,90 & Sem dados & Sem dados & 5,60 & Sem dados \\
\hline Média $(\mathrm{R} \$ / \mathbf{k g})$ & 3,11 & 4,73 & 4,60 & 4,60 & 5,53 & 4,00 \\
\hline
\end{tabular}

Tabela 8 - Custo específico de produção anual para o policultivo tradicional.

\begin{tabular}{|c|c|c|c|c|}
\hline Descriminação & Unidade & $\begin{array}{c}\text { Custo } \\
\text { Unitário } \\
\text { (R\$) }\end{array}$ & Quantidade & $\begin{array}{l}\text { Custo } \\
\text { total } \\
\text { (R\$) }\end{array}$ \\
\hline Alevinos Carpa Húngara & un & 0,15 & 1925 & 288,75 \\
\hline Alevinos Carpa-capim & un & 0,15 & 1925 & 288,75 \\
\hline Alevinos Carpa Prateada & un & 0,15 & 825 & 123,75 \\
\hline Alevinos Carpa Cabeça-grande & un & 0,15 & 825 & 123,75 \\
\hline Milho & $\mathrm{Kg} / \mathrm{dia}$ & 0,4 & $9.491,62$ & $3.796,65$ \\
\hline & & & Total & $4.621,65$ \\
\hline
\end{tabular}

Tabela 9 - Levantamento da receita bruta do policultivo tradicional ( $1^{\circ}$ Cultivo) com densidade de 5000 peixes/ ha.

\begin{tabular}{lccc}
\hline \hline \multicolumn{1}{c}{ Espécie } & $\begin{array}{c}\text { Produção } \\
\text { (kg/ha/ano) }\end{array}$ & $\begin{array}{c}\text { Preço por kg } \\
\text { (Média R\$/kg) }\end{array}$ & $\begin{array}{c}\text { Receita } \\
\text { Bruta (R\$) }\end{array}$ \\
\hline Carpa Húngara & $1.661,60$ & 3,11 & $5.167,58$ \\
Carpa-capim & 762,60 & 4,73 & $3.607,10$ \\
Carpa Prateada & 465,00 & 4,60 & $2.139,00$ \\
Carpa Cabeça-grande & 372,00 & 4,60 & $1.711,20$ \\
& & Total & $\mathbf{1 2 . 6 2 4 , 8 8}$ \\
\hline \hline
\end{tabular}


Tabela 10 - Custo específico de produção anual para o policultivo P25.

\begin{tabular}{|c|c|c|c|c|}
\hline Descriminação & Unidade & $\begin{array}{c}\text { Custo } \\
\text { Unitário } \\
\text { (R\$) }\end{array}$ & Quantidade & $\begin{array}{l}\text { Custo } \\
\text { total } \\
\text { (R\$) }\end{array}$ \\
\hline Alevinos Carpa Húngara & un & 0,15 & 1444 & 216,6 \\
\hline Alevinos Carpa-capim & un & 0,15 & 1925 & 288,75 \\
\hline Alevinos Carpa Prateada & un & 0,15 & 619 & 92,85 \\
\hline Alevinos Carpa Cabeça-grande & un & 0,15 & 619 & 92,85 \\
\hline Alevinos Jundiá & un & 0,17 & 481 & 81,77 \\
\hline Alevinos Tilápia & un & 0,28 & 413 & 115,64 \\
\hline Ração Crescimento (até 60 dias) & $\mathrm{kg}$ & 3,33 & 45,00 & 149,85 \\
\hline Ração Engorda 32\% Proteína Bruta & $\mathrm{Kg} / \mathrm{dia}$ & 1,30 & 1387,19 & 1803,34 \\
\hline \multirow[t]{2}{*}{ Milho } & $\mathrm{Kg} / \mathrm{dia}$ & 0,40 & 4296,56 & 1718,62 \\
\hline & & & Total & $4.560,27$ \\
\hline
\end{tabular}

Tabela 11 - Levantamento da receita bruta do policultivo P25 ( $1^{\circ}$ Cultivo $)$ com densidade de 5000 peixes/ha.

\begin{tabular}{|c|c|c|c|}
\hline Item & $\begin{array}{c}\text { Produção } \\
\text { (kg/ha/ano) }\end{array}$ & $\begin{array}{c}\text { Preço por Kg } \\
\text { Média RS } \\
\text { (R\$) } \\
\end{array}$ & $\begin{array}{c}\text { Receita } \\
\text { Bruta } \\
\text { (R\$) } \\
\end{array}$ \\
\hline $\begin{array}{l}\text { Carpa Húngara } \\
\text { Carpa-capim } \\
\text { Carpa Prateada } \\
\text { Carpa Cabeça-grande } \\
\text { Jundiá } \\
\text { Tilápia }\end{array}$ & $\begin{array}{c}2.058,40 \\
1.078,80 \\
468,10 \\
607,60 \\
248,00 \\
409,20\end{array}$ & $\begin{array}{l}3,11 \\
4,73 \\
4,60 \\
4,60 \\
5,53 \\
4,00 \\
\text { Total }\end{array}$ & $\begin{array}{l}6.401,62 \\
5.102,72 \\
2.153,26 \\
2.794,96 \\
1.371,44 \\
1.636,80 \\
19.460,80\end{array}$ \\
\hline
\end{tabular}

pode ser devido a melhor interação das espécies na cadeia alimentar, onde apesar de ser substituído $25 \%$ das carpas o seu desempenho zootécnico chegou a aumentar $24 \%$, no caso da carpa-húngara.

Outro fator que justifica o aumento da receita bruta neste policultivo é a inserção de jundiás e tilápias-do-Nilo cuja produção somada chega a $650 \mathrm{~kg}$, e o seu preço de venda é aproximadamente $40 \%$ maior do que o da carpa-húngara.

O policultivo P50 tem um custo específico de produção anual referente a gastos com alevinos de carpas, jundiás e tilápias-do-Nilo, com milho e ração que é utilizado na alimentação destas, perfazendo um custo adicional de $\mathrm{R} \$ 7609,40 /$ ano, conforme apresentado na Tabela 12.

Para o policultivo com $50 \%$ de substituição, valores de produção e receita, são apresentados na Tabela 13. Em comparação com o policultivo tradicional, esse sistema apresenta-se ainda mais rentável, gerando uma receita bruta de $\mathrm{R} \$ 19595,97$ ha/ano.

O policultivo P75 tem um custo específico de produção anual referente a gastos com alevinos de

Tabela 12 - Custo específico de produção anual para o policultivo P50.

\begin{tabular}{|c|c|c|c|c|}
\hline Descriminação & $\begin{array}{c}\text { Custo } \\
\text { Unitário } \\
\text { (R\$) }\end{array}$ & Unidade & Quantidade & $\begin{array}{l}\text { Custo } \\
\text { total } \\
\text { (R\$) } \\
\end{array}$ \\
\hline Alevinos Carpa Húngara & 0,15 & un & 963 & 144,45 \\
\hline Alevinos Carpa-capim & 0,15 & un & 1925 & 288,75 \\
\hline Alevinos Carpa Prateada & 0,15 & un & 413 & 61,95 \\
\hline Alevinos Carpa Cabeça-grande & 0,15 & un & 413 & 61,95 \\
\hline Alevinos Jundiá & 0,17 & un & 963 & 163,71 \\
\hline Alevinos Tilápia & 0,28 & un & 825 & 231,00 \\
\hline Ração Crescimento (até 60 dias) & 3,33 & $\mathrm{Kg}$ & 45 & 149,85 \\
\hline Ração Engorda 32\% Proteína Bruta & 1,30 & $\mathrm{Kg}$ & 3817,08 & 4962,04 \\
\hline \multirow[t]{2}{*}{ Milho } & 0,40 & $\mathrm{Kg}$ & 3864,24 & 1545,70 \\
\hline & & & Total & $7.609,40$ \\
\hline
\end{tabular}

Tabela 13 - Levantamento da Receita Bruta do policultivo P50 ( $1^{\circ}$ Cultivo) com densidade de 5000 peixes/ ha.

\begin{tabular}{lccc}
\hline \hline \multicolumn{1}{c}{ Item } & $\begin{array}{c}\text { Produção } \\
\text { (kg/ha/ano) }\end{array}$ & $\begin{array}{c}\text { Preço por Kg } \\
\text { Média RS } \\
(\mathbf{R} \$)\end{array}$ & $\begin{array}{c}\text { Receita } \\
\text { Bruta } \\
\text { (R\$) }\end{array}$ \\
\hline Carpa Húngara & $1.543,80$ & 3,11 & $4.801,22$ \\
Carpa-capim & $1.184,20$ & 4,73 & $5.601,27$ \\
Carpa Prateada & 279,00 & 4,60 & $1.283,40$ \\
Carpa Cabeça-grande & 502,20 & 4,60 & $2.310,12$ \\
Jundiá & 458,80 & 5,53 & $2.537,16$ \\
Tilápia & 765,70 & 4,00 & $3.062,80$ \\
& & \multicolumn{3}{c}{ Total } & $\mathbf{1 9 . 5 9 5 , 9 7}$ \\
\hline \hline
\end{tabular}


Tabela 14 - Custo específico de produção anual para o policultivo P75.

\begin{tabular}{|c|c|c|c|c|}
\hline Descriminação & $\begin{array}{c}\text { Custo } \\
\text { Unitário } \\
\text { (R\$) }\end{array}$ & Unidade & Quantidade & $\begin{array}{c}\text { Custo } \\
\text { total (R\$) }\end{array}$ \\
\hline Alevinos Carpa Húngara & 0,15 & un & 481 & 72,15 \\
\hline Alevinos Carpa-capim & 0,15 & un & 1925 & 288,75 \\
\hline Alevinos Carpa Prateada & 0,15 & un & 206 & 30,90 \\
\hline Alevinos Carpa Cabeça-grande & 0,15 & un & 206 & 30,90 \\
\hline Alevinos Jundiá & 0,17 & un & 1444 & 245,48 \\
\hline Alevinos Tilápia & 0,28 & un & 1238 & 346,64 \\
\hline Ração Crescimento (até 60 dias) & 3,33 & $\mathrm{~kg}$ & 45 & 149,85 \\
\hline Ração Engorda $32 \%$ Proteína Bruta & 1,30 & $\mathrm{Kg}$ & 6541,40 & 8445,32 \\
\hline \multirow[t]{2}{*}{ Milho } & 0,40 & $\mathrm{Kg}$ & 2178,03 & 871,11 \\
\hline & & & Total & $10.481,10$ \\
\hline
\end{tabular}

Tabela 15 - Levantamento da receita bruta do policultivo P75 ( $1^{\circ}$ Cultivo) com densidade de 5000 peixes/ ha.

\begin{tabular}{|c|c|c|c|}
\hline Item & $\begin{array}{l}\text { Produção } \\
\text { (kg/ha/ano) }\end{array}$ & $\begin{array}{l}\text { Preço por Kg } \\
\text { Média RS } \\
(R \$)\end{array}$ & $\begin{array}{c}\text { Receita } \\
\text { Bruta } \\
\text { (R\$) }\end{array}$ \\
\hline Carpa Húngara & $1.413,60$ & 3,11 & $4.396,30$ \\
\hline Carpa-capim & 961,00 & 4,73 & $4.545,53$ \\
\hline Carpa Prateada & 179,80 & 4,60 & 827,08 \\
\hline Carpa Cabeça-grande & 124,00 & 4,60 & 570,40 \\
\hline Jundiá & 564,20 & 5,53 & $3.120,03$ \\
\hline \multirow[t]{2}{*}{ Tilápia } & $1.227,6$ & 4,00 & $4.910,40$ \\
\hline & & Total & $18.369,74$ \\
\hline
\end{tabular}

Tabela 16 - Resultados da Avaliação Econômica para os policultivos estudados.

\begin{tabular}{lcccc}
\hline \hline Método & $\begin{array}{c}\text { Policultivo } \\
\text { Tradicional }\end{array}$ & $\begin{array}{c}\text { P25 (25\% de } \\
\text { substituição) }\end{array}$ & $\begin{array}{c}\text { P50 (50\% de } \\
\text { substituição) }\end{array}$ & $\begin{array}{c}\text { P75 (75\% de } \\
\text { substituição) }\end{array}$ \\
\hline VPL & $\mathrm{R} \$ 29.259,01$ & $\mathrm{R} \$ 114.045,35$ & $\mathrm{R} \$ 77.350,26$ & $\mathrm{R} \$ 26.155,39$ \\
TIR & $15,61 \%$ & $38,96 \%$ & $29,08 \%$ & $14,69 \%$ \\
VA & $\mathrm{R} \$ 2.325,94$ & $\mathrm{R} \$ 9.066,01$ & $\mathrm{R} \$ 6.148,94$ & $\mathrm{R} \$ 2.079,22$ \\
Payback & 5,7 anos & 2,5 anos & 3,3 anos & 6 anos \\
\hline \hline
\end{tabular}

carpas, jundiás e tilápias-do-Nilo, com milho e ração que é utilizado na alimentação destas, perfazendo um custo adicional de $\mathrm{R} \$ 10481,10 / a n o$, conforme apresentado na Tabela 14.

A receita obtida no policultivo com $75 \%$ de substituição (Tabela15) superou apenas a obtida no policultivo tradicional, isso pode ser devido a maior substituição das carpas, ocasionando uma menor biomassa de carpas filtradoras, que, dentre as carpas tem o maior preço de venda.

A Tabela 16 apresenta os valores de VPL, TIR, VA e payback dos diferentes policultivos propostos.

Todos os policultivos propostos apresentaram VPL e VA positivos e TIR superiores à TMA $(6,17 \%)$, evidenciando que o investimento em qualquer destes sistemas de produção de peixes é atrativo e viável do ponto de vista econômico.

O payback para os policultivos P25 e P50 foi menor que o policultivo tradicional mostrando que o retorno do capital investido nestes policultivos propostos se dá em um tempo menor que o policultivo tradicional.

\section{CONCLUSÕES}

O policultivo de carpas mostrou-se ser uma atividade apropriada para a pequena propriedade e a substituição parcial das carpas por jundiás e tilápiasdo-Nilo é uma alternativa adequada para a piscicultura no RS, obtendo um aumento significativo na produtividade de biomassa.

A receita bruta obtida nos policultivos propostos com substituição parcial das carpas é aproximadamente $55 \%$ maior do que a obtida no policultivo tradicional.

Todos os policultivos têm o mesmo Investimento Inicial para a implantação, porém o policultivo P25 é o que apresenta o menor gasto anual de manutenção.

Em face dos resultados obtidos, sugere-se a utilização do Policultivo com $25 \%$ de substituição das carpas por jundiás e tilápias-do-Nilo, por este sistema apresentar o maior rendimento de biomassa, o maior Valor Presente Líquido, a maior Taxa Interna de Retorno e o menor payback. 


\section{REFERÊNCIAS}

Abdelghany, A.E. \& Ahmad, M.H. 2002. Effects of feeding rates on growth and production of Nile tilapia, commom carp and silver carp polycultured in fertilized ponds. Aquac. Res. 33: 415-423.

Barcellos, L.J.G.; Kreutz, L.C.; Rodrigues, L.B.; Fioreze, I.; Quevedo, R.M.; Cericato, L.; Conrad, J.; Fagundes, M.; Soso, A.; Lacerda, L.A. \& Terra, S. 2003. Hematological and biochemical characteristics of male jundiá (Rhamdia quelen Quoy \& Gaimard Pimelodidae): changes after harvest acute stress. Aquac. Res. 34: 1465-1469.

Barcellos, L.J.G. 2006. Policultivo de Jundiás, Tilápias e Carpas: uma alternativa para a piscicultura Riograndense. $1^{\circ}$ Edição. Editora da UPF, Passo Fundo, 127p.

Bruni, A.L. \& Famá, R. 2003. As decisões de investimentos. Atlas, São Paulo, 264p.

Buarque, C. 2004. Avaliação econômica de projetos. $28^{\circ}$ Reimpressão. Elsevier, São Paulo, 266p.

Cohen, E. \& Franco, R. 2000. Avaliação de projetos sociais. $4^{\circ}$ Edição. Vozes, Petrópolis, 312p.

Costa, F.S.da. 2008. Avaliação econômica do sistema de policultivo de camarões marinhos (Litopenaeus vannamei) com tilápia (Oreochromis niloticus) em diferentes densidades de estocagem. Tese de Mestrado. Universidade Federal de Santa Catarina. 30p.

FAO - Food and Agriculture Organization of the United Nations. Panorama da Aquicultura. 2007. Disponível em: <http://www.fao.org/fi/default. asp>. Acesso em: 20 nov. 2009

Casarotto Filho, N. \& Kopittke, B.H. 1988. Análise de investimentos: matemática financeira, engenharia econômica, tomada de decisão. $8^{\circ}$ Edição, Atlas, São Paulo, 468p.

Galesne, A.; Fensterseifer, J.E. \& Lamb, R. 1999. Decisões de investimentos da empresa. Atlas, São Paulo, 295p.

Gomes, L.C.; Golombieski, J.I.; Regina, A.; Gomes, C. \& Baldisseroto, B. 2000. Biology of Rhamdia quelen (Teleostei, Pimelodidae). Ciênc. Rural 30: 179-185.

Graeff, A.; Kreuz, C.; Pruner, E. \& Spengler, M. 2001. Viabilidade econômica de estocagem de alevinos de carpa comum (Cyprinus carpio Var. Specularis) no inverno em alta densidade. Rev. Bras. Zootecn. 30(4):1150-1158.

Instituto Brasileiro do Meio Ambiente e dos Recursos Naturais Renováveis (IBAMA). Estatística Pesqueira do Brasil. 2005. Disponível em: <http:// www.ibama.gov.br>. Acesso em: 12 jan. 2010

Kassai, J.R.; Kassai, S.A. \& Neto, A.A. 2000. Retorno de Investimento: Abordagem matemática e contábil do lucro empresarial. Atlas, São Paulo, $277 p$.

Kestmont, P. 1995. Different systems of carp production and their impacts on the environment. Aquaculture 129: 347-372.

Lindemeyer, R.M. 2008. Análise da viabilidade econômico-financeira do uso do biogás como fonte de energia elétrica. Trabalho de Conclusão de Curso. Universidade Federal de Santa Catarina. $105 p$.

Passo Fundo. Site do município. Disponível em: < http:// www.pmpf.rs.gov.br/secao.php?p=158\&a=3>. Acesso em: 14 nov. 2009.

Pereira, S.M. 2009. Estudo dos custos operacionais e da viabilidade de implantação de um sistema de coleta de dejetos de suínos para a geração de bioenergia no município de Toledo-SC. Tese de Mestrado. Universidade Estadual do Oeste do Paraná - UNIOESTE. 110p.

Ritvo, G.; Kochba, M. \& Avnimelech, Y. 2004. The effects of common carp bioturbation on fishpond soil. Aquaculture 242: 345-356.

Silva, L. da; Kreutz, L.; Souza, S. de; Bedin, A.; Barcellos, L.; Finco, J.; Ritter, F. \& Quevedo, R. 2006. Alternative species for traditional carp polyculture in southern South America: Initial growing period. Aquaculture. 255: 417-428.

Silva, J.R. 2008. Análise da viabilidade econômica da produção de peixes em tanques-rede no reservatório de Itaipu. Tese de Mestrado. Universidade Federal de Santa Maria. 142p.

Souza, S.M.G. \& Barcellos, L.J.G. 1998. Piscicultura: Recria e Engorda. SENAR-RS, Porto Alegre, 188p.
Submetido: Março/2013 Revisado: Janeiro/2014 Aceito: Março/2014 